\title{
Learning from PISA
}

\section{Reasons and remedies for student under-performance in reading, maths and science}

\section{Example of a science exercise set in PISA, taken from PISA 2000, OECD (texts and questions are abridged from the originals)}

Text 1:

A German physician named Ignaz Semmelweis (1818-1865) noted the high rate of mortality from puerperal fever in post-natal women in the hospital in which he worked. Ignorant of the cause, though sceptical of the traditional explanations (changes in the air, extra terrestrial influences or earthquakes), he recorded the numbers of deaths in two wards of the hospital over several years and plotted the results.

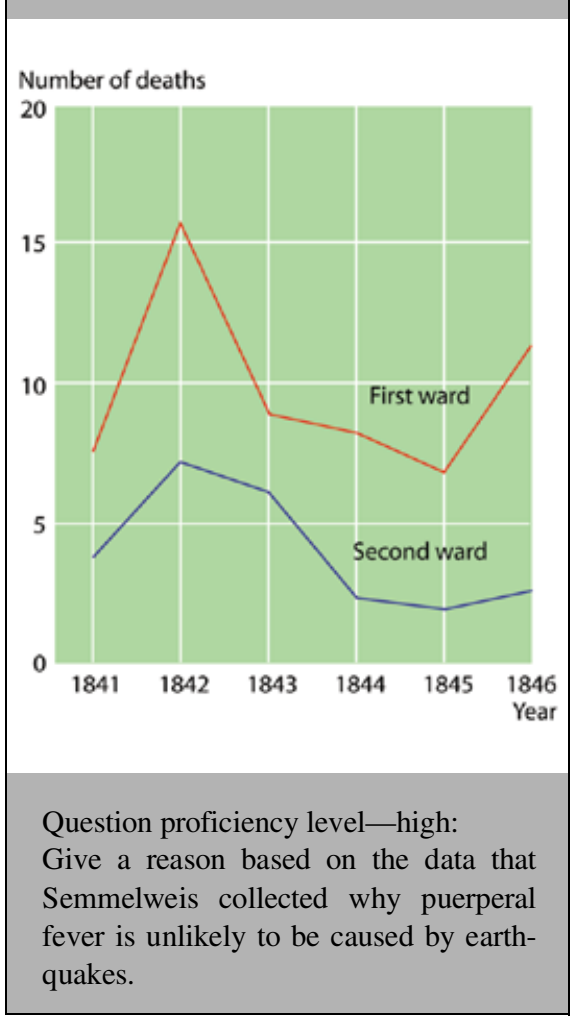

The great competition is over, the judges have given their marks and the chalk dust has settled over the arena. A few hurt prides pick themselves up off the floor, and set about the painful task of finding out what went wrong and why they did not fare as well as they expected. This is not the aftermath of the winter Olympics, rather the results of the PISA study, the Programme for International Student Assessment. The largest world-wide test of student performance ever conducted, it provides a much needed assessment of how well various countries educate their children. And PISA served up a can of worms to some diners who can afford to pay for duck à l'orange, while other less wealthy guests came away substantially more satisfied. Many of the fatter countries had quietly been intellectually malnourishing their most important resource: school children.

Investment in basic requirements is important, but what PISA revealed is that money is certainly not everything in education. It is other important factors, notably student motivation, teacher training, the role of parents and a well-established infrastructure, that have put countries such as Finland and (South) Korea at the top of the list. For other countries, many of whom spend more money per student, PISA has been a rude awakening to the urgent need for change. In Germany it has stirred an intense debate-aside from the mutual finger-pointing that usually follows bad results-as to how to achieve a long overdue and radical overhaul of the country's education system. Barely a day passes without a press release concerning 'reforms', 'improvements' and 'opportunities' in education.

To appreciate the significance of PISA, it pays to know how the study was conducted. More than 250000 15-year-olds in 32 countries took a $2 \mathrm{~h}$ paper and pencil test comprising $45 \%$ multiple choice questions, $45 \%$ requiring self-generated answers and $10 \%$ limited range answers. It was supplemented by a student questionnaire and a questionnaire to be completed by school principals. In reading literacy, the PISA study defines five levels of proficiency that range from identifying one obvious piece of information in a text (level 1) to extracting deeply embedded information, evaluating it and inferring a conclusion (level 5). Worryingly, $10 \%$ or more of the students in some European countries failed to reach even level 1 . Scores in mathematics and science are given according to three levels of proficiency, ranging from simply applying common knowledge (lowest), to the ability to relate given data and evaluate different theories (highest). Performances in a particular exercise are scored on a scale of $0-800$ points depending on the difficulty of the question and the quality of the answer given.

Text 2:

In the hospital, Semmelweis noted that students working in the first ward routinely performed autopsies on women who had died the previous day before examining women who were about to give birth. Most did not wash their hands after dissection, and a colleague of Semmelweis died of an infection resembling puerperal fever after cutting himself during an autopsy.

Question proficiency level-middle:

Many diseases may be cured with antibiotics. However, the success of some antibiotics against puerperal fever has diminished in recent years. Why?

Question proficiency level-low:

Today, high-temperature washing of bed sheets, is among many other measures taken to reduce the risk of contracting fevers. Why are high temperatures effective? 


\section{analysis}

Table I. Leading or lagging: how countries fared according to average performance across reading, mathematics and science

\begin{tabular}{|l|c|}
\hline \multicolumn{2}{|c|}{ Reading literacy } \\
\hline Country & Mean score \\
\hline Finland & 546 \\
\hline Canada & 534 \\
\hline New Zealand & 529 \\
\hline Australia & 528 \\
\hline Ireland & 527 \\
\hline Korea & 525 \\
\hline UK & 523 \\
\hline Japan & 522 \\
\hline Sweden & 516 \\
\hline Austria & 507 \\
\hline Belgium & 507 \\
\hline Iceland & 507 \\
\hline Norway & 505 \\
\hline France & 505 \\
\hline United States & 504 \\
\hline Denmark & 497 \\
\hline Switzerland & 494 \\
\hline Spain & 493 \\
\hline Czech Republic & 492 \\
\hline Italy & 487 \\
\hline Germany & 484 \\
\hline Liechtenstein & 483 \\
\hline Hungary & 480 \\
\hline Poland & 479 \\
\hline Greece & 474 \\
\hline Portugal & 470 \\
\hline Russian Fed. & 462 \\
\hline Latvia & 458 \\
\hline Luxembourg & 441 \\
\hline Mexico & 422 \\
\hline Brazil & 396 \\
\hline Non-OECD & 5 \\
\hline
\end{tabular}

Non-OECD countries are in black

Key:

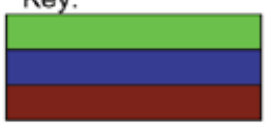

Statistically significantly above the OECD average

Not statistically significantly different from the OECD average

Statistically significantly below the OECD average

Data taken from PISA 2000, OECD.

As much as PISA can be criticised—as can any study - it is surely indicative of the average standard of reading, mathematics and science in schools. Similar country rankings across all three areas tested reveal that there are systematic forces at work in any one country (Table I). But PISA was not merely a test of academic ability; it was not designed to test excellence, memorised knowledge or particular aptitude for abstract academic reasoning. As its title, 'knowledge and skills for life', suggests, it tested the ability to complete exercises deliberately engineered to be highly relevant to real life (see boxes on previous page). Clearly, memorising the lanthanides, interpreting 18th Century literature or solving a complex equation are not necessarily important when it comes to understanding an insurance policy or calculating the value-added tax on a new

\begin{tabular}{|l|c|}
\hline \multicolumn{2}{|c|}{ Mathematical literacy } \\
\hline Country & Mean score \\
\hline Japan & 557 \\
\hline Korea & 547 \\
\hline New Zealand & 537 \\
\hline Finland & 536 \\
\hline Australia & 533 \\
\hline Canada & 533 \\
\hline Switzerland & 529 \\
\hline UK & 529 \\
\hline Belgium & 520 \\
\hline France & 517 \\
\hline Austria & 515 \\
\hline Denmark & 514 \\
\hline Iceland & 514 \\
\hline Liechtenstein & 514 \\
\hline Sweden & 510 \\
\hline Ireland & 503 \\
\hline Norway & 499 \\
\hline Czech Republic & 498 \\
\hline United States & 493 \\
\hline Germany & 490 \\
\hline Hungary & 488 \\
\hline Russian Fed & 478 \\
\hline Spain & 476 \\
\hline Poland & 470 \\
\hline Latvia & 463 \\
\hline Italy & 457 \\
\hline Portugal & 454 \\
\hline Greece & 447 \\
\hline Luxembourg & 446 \\
\hline Mexico & 387 \\
\hline Brazil & 334 \\
\hline & \\
\hline & \\
\hline
\end{tabular}

\begin{tabular}{|l|c|}
\hline \multicolumn{2}{|c|}{ Scientific literacy } \\
\hline Country & Mean score \\
\hline Korea & 552 \\
\hline Japan & 550 \\
\hline Finland & 538 \\
\hline UK & 532 \\
\hline Canada & 529 \\
\hline New Zealand & 528 \\
\hline Australia & 528 \\
\hline Austria & 519 \\
\hline Ireland & 513 \\
\hline Sweden & 512 \\
\hline Czech Republic & 511 \\
\hline France & 500 \\
\hline Norway & 500 \\
\hline United States & 499 \\
\hline Hungary & 496 \\
\hline Iceland & 496 \\
\hline Belgium & 496 \\
\hline Switzerland & 496 \\
\hline Spain & 491 \\
\hline Germany & 487 \\
\hline Poland & 483 \\
\hline Denmark & 481 \\
\hline Italy & 478 \\
\hline Liechtenstein & 476 \\
\hline Greece & 461 \\
\hline Russian Fed. & 460 \\
\hline Latvia & 460 \\
\hline Portugal & 459 \\
\hline Luxembourg & 443 \\
\hline Mexico & 422 \\
\hline Brazil & 375 \\
\hline & \\
\hline & \\
\hline
\end{tabular}

kitchen. And these are exactly the types of task that create problems for many students even in richer countries.

Also, PISA did more than measure student performance; via the student and principal questionnaire, it analysed underlying factors other than the quality of the education system. As if confirming the obvious, it singles out motivation as the main

PISA served up a can of worms to some diners who can afford to pay for duck à l'orange

determinant of student performance. However, this obvious inference is complemented by a very careful dissection of the contexts in which student motivation thrives or perishes. PISA shows that low family wealth and social standing can be compensated for by cultural richness at home and in extra-curricular pursuits. This, however, only works in a country that succeeds in integrating all layers of society. In contrast, in Germany, where many children from high-income families are top performers, many children from immigrant or poor families are barely able to acquire the skills necessary to master life. Other factors such as adequate equipment and resources in school are important, but even poorer schools can produce excellent results if their teachers are well-trained and highly motivated, and the learning environment is conducive.

When all factors are taken into consideration, however, the question still remains: how does one inspire children to the point at which their own interest in a 


\section{analysis}

subject is motivation enough to learn it? Although intelligence is a prerequisite, it is ultimately teachers who have to kindle the spark of interest and motivation in the young and keep it burning for many years of education. Sadly, many teachers are regarded by the system as transmitters of knowledge, not inspirers of would-be scientists, literati or entrepreneurs. Especially in the natural sciences, where there is so much background information for a student to assimilate before being able to grasp the most exciting developments of recent years, the basics cannot afford to be made boring. Fascination must be nurtured from the beginning. And if politicians are to cultivate the next generation to be the mixture of informed citizens, academics and leaders of industry that we need we must inspire the inspirers, select the best, and look after them well.

That, after all, is what is done in two of the countries that performed best in the PISA study: Finland and Korea. In Finland,

It is ultimately teachers who kindle the spark of interest and motivation and keep it burning for many years

an education system in which $95 \%$ of students take the equivalent of the Baccalaureat (Abitur/A-levels), and 70\% go on to further education, is supported by a teaching profession that is at once highly meritocratic, highly respected and highly cared for. As Kirsi Lindroos, Director of the General Education Division of the Finnish Ministry of Education, remarked, 'it is very important that the Finnish municipalities take care of their teachers,' and 'it is very common for teachers to take one term away from school to undertake their own studies.' The Finns recognise that extra-curricular pursuits are as important for teachers as for students.

An enlightened approach is also practiced in the administration of the Finnish curriculum. Although basic requirements are stipulated nationally, municipalities and schools have the freedom to define their own curricula. How these are taught is perhaps more revolutionary, as Lindroos explained, '[teachers] have possibilities to develop and use [their] own systems.' Teacher creativity, it appears, is sought and nurtured. Furthermore, schools are 'very much involved in self-evaluation' as Lindroos puts it, a mechanism that gives fast feedback

Korean teachers also appear well catered for, and here again the profession is vastly over-subscribed. 'If you are a Korean teacher, you are already in the top hand-full of professionals in terms of motivation,' according to Kooghyang Ro, a research fellow at the Korea Institute of Curriculum \& Evaluation. As she put it, 'everybody wants to be a teacher.' And teaching is certainly not a dead art; teachers are increasingly interested in learning, and are enthusiastic about their subject, receiving further education through a formal system of professional development. Although it may not be the most highly paid job, teaching is a highly respected profession in Korea, as it is in other Asian

and recommendations for improvement.

Being a teacher in Finland is no easy option-positions in teaching are oversubscribed by anything from 3:1 to $5: 1$. And to be any kind of teacher requires a university education: 5 years to become a primary teacher, and a minimum of 6 years societies based on Confucianism or Buddhism, traditions that hold teachers in the highest possible regard.

Per capita spending on students is not as decisive a factor as one might think among the countries scrutinised in PISA. Clearly, some countries' poor performance is a direct result of poverty. Mexico and Brazil have the lowest per student expenditure and are regularly to be found at the bottom of the league. But the fact that they are disproportionately worse than others indicates that additional factors are at work-social disintegration and lack of infrastructure. Indeed, the slight correlation between expenditure per student and average student performance that PISA demonstrates seems to be largely incidental (Figure 1). Korea, for example, spends below average, but excels. Finland performs equally well, and spends averagely. The USA has almost the highest expenditure per imbalances that plague some countries

In the natural sciences, there is so much background information to assimilate that these basics cannot afford to be made boring

with professionals from the social sector, and it is not uncommon for a teacher to visit the home of a student. That the state really cares is evident: of the 4070 schools in Finland, only 66 are private. And care it has to, because with a population of only 5 million, every teacher and every child matters for Finland's rapidly growing economy. student, and performs consistently below average. Interestingly, Switzerland and Denmark are also in this high spend:performance ratio group, but worst of the high spenders in terms of value for money is Italy, a regular poor performer.

PISA surprises the reader because of some of the apparent contradictions it raises. Regardless of the fact that Germany 


\section{analysis}

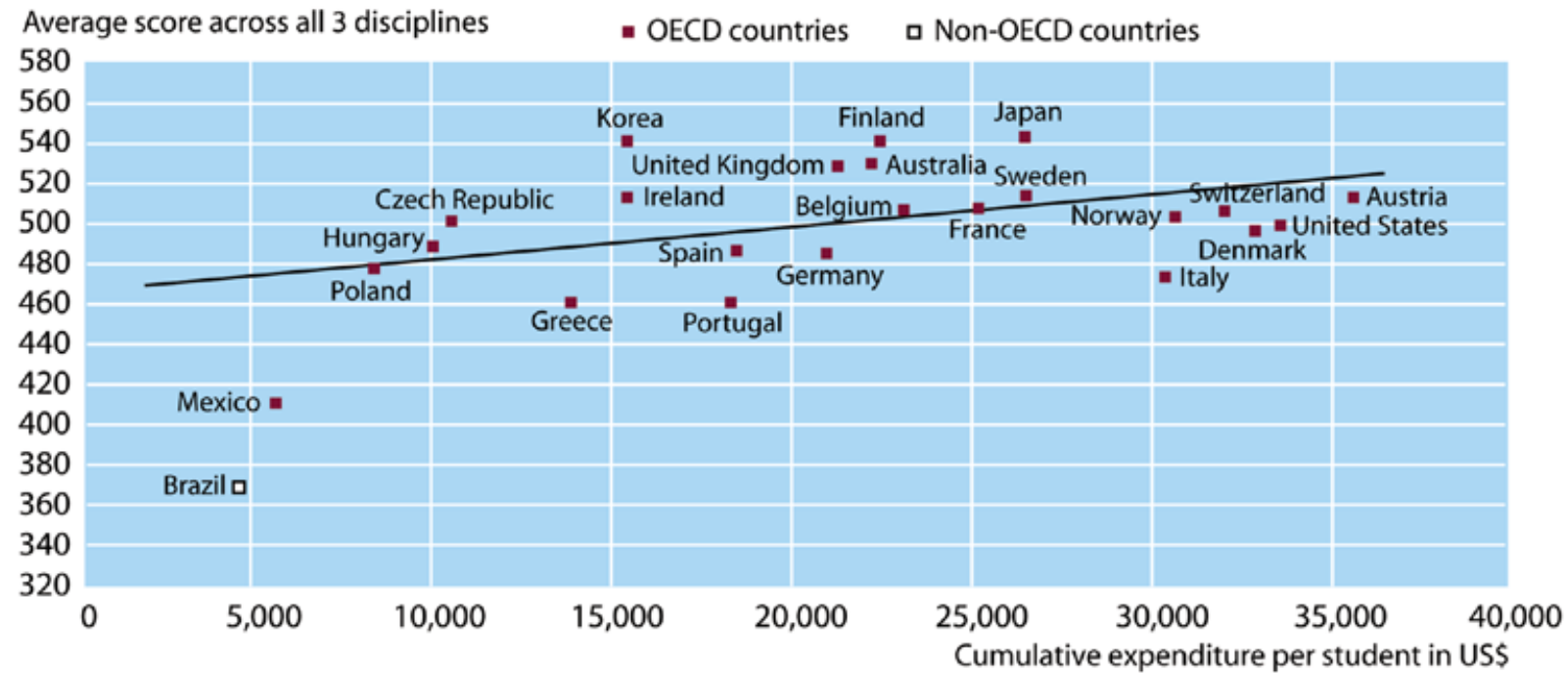

Fig. 1. Value for money? Relationship between average performance across the combined reading, mathematical and scientific proficiency scales and cumulative expenditure per student on educational institutions up to age 15 in US\$, converted using purchasing power parities. Spending on education is related in a very remote way to pupil performance (black trend line calculated only on OECD country data). Reproduced from PISA 2000 , OECD.

spends averagely on education, it is viewed as a successful, productive country that houses some of the most respected seats of learning and culture in Europe, and has had its fair share of Nobel laureates.

\section{Teaching is a highly respected profession in Asian societies based on Confucianism or Buddhism, traditions that hold teachers in the highest possible regard}

Access to culture and libraries is affordable and the German constitution guarantees free and equal access to education and learning to all its citizens. And yet its students consistently perform well below the average.

What are the messages for a country like Germany, whose wealth does not stand in the way of better performance? More motivation in children and teachers, according to State Secretary Uwe Thomas from the Federal Ministry for Education and Research, who sees the lack of these magic ingredients as the main cause for Germany's under-performance. Other factors, such as a system that selects students for higher education too early-between 10 and 12 years, as opposed to 15 years as in Finland-and the waning importance of classical subjects, such as reading, physics, maths and literature, also play a role. 'Solidarity in learning'-i.e. collaborative learning-is also missing, thinks Thomas. The way out of the mire is to motivate teachers, students and parents back to the mentality that 'going to school is one of the best experiences in life', as he put it.

The wide spread of performance in Germany also indicates that school does not expiate social inequality, and this really is surprising for a central European country. In the USA, social inequality is expected to colour student performance, and the USA's high average expenditure per student partly results from very high spending on 'special needs students'. But on the face of it, Germany does not appear to have such problems. This is not true. Many now agree that lack of social integration is a matter for concern for the country. Without doubt, the introduction of whole-day school will help, but another PISA finding will also have to be

Teaching must never be considered the relating of

information, rather a dynamic communication process

addressed: German pupils on average complain loudest that their teachers do not pay enough attention to them. This is compounded by the observation that a question-asking culture is in general not nurtured in the classroom. Whole-day school is of no use unless teachers can make it a motivating experience. And so we are back where we started-with teachers. A child's upbringing rests with parents up to the school door; thereafter, teachers are literally in loco parentis.

In the sciences, especially in this fastmoving age, it is vital that teachers continue their learning experience as long as they are teaching. Another important component of the dynamism seen in Finland and Korea is the meritocratic system of selecting teachers, which Kooghyang Ro referred to as 'selecting the cream off the top'. Teaching is not something that anyone can do. Furthermore, it must never be considered the relating of once learnt information, rather a dynamic communication process between the very latest in science and the eager minds waiting to be inspired by it. Korean and Finnish teachers are very well catered for in this respect. As Kooghyang Ro remarked, '[in Korea] science educators are very keen to [keep abreast of] scientific developments'. All countries that suffer from an undynamic teaching force that has largely been neglected in terms of further education must realise that teaching begins with learning, and learning never ends.

\section{Andrew Moore}

DOI: 10.1093/embo-reports/kvf082 